\title{
Héroes y villanos del Nuevo Mundo en la Historia General y natural de las Indias de Gonzalo Fernández de Oviedo y Valdés*
}

\author{
Alexandre Coello de la Rosa \\ Universitat Pompeu Fabra
}

Autores recientes insisten en que las crónicas de Indias son un conjunto de narraciones, relatos, estilos de contar las experiencias vividas en el Nuevo Mundo, impregnadas de providencialismo, mesianismo y de otros juicios de valor procedentes de su formación retórica y de la pastoral judeocristiana. La Historia de Fernández de Oviedo es un ejemplo perfecto. Aunque la Historia contiene ciertos rasgos de estilo propios de un género cuyo carácter tiene que ver indudablemente con la historiografía, incorpora múltiples planos alegóricos e imaginativos pertenecientes a una formación textual literaria. En este artículo vamos a analizar la construcción de un modelo de héroe cristiano, y su reverso, como figuras literarias en la elaboración de una historiografía colonial e imperialista.

PAlabras ClaVE: Gonzalo Fernández de Oviedo, héroes, retórica, historia moral.

Modern scholars analyze the chronicles of the Indies as a set of accounts, reports, ways of narrating the lived experiences in the New World, which were tinged with providentialism, mesianism and other value judgments from their rhetoric structure and judeoChristian pastoral. The Historia by Fernández de Oviedo (1478-1557) is a perfect example. Although the Historia contains various elements of style that are representative of a genre whose main quality has undoubtedly to do with historiography, it incorporates many allegorical and imaginative levels belonging to a literary textual formation. In this article I shall explore both the construction of a model of Christian hero, and its reverse, as literary figures in the elaboration of a imperialistic and colonial historiography.

KEYwORDS: Gonzalo Fernández de Oviedo, heroes, rhetoric, moral history.

"La hystoria de las cossas passadas tiene valor y precio inestimable porque es conseruadora de la memoria y mensajera de la verdad y da mucha causa de deleyte y de honesta vtilidad... E como quiera que los preceptos y doctrinas de la philosophía informen y enseñen la vida de los hombres con mucho prouecho y hermosura, con mayor vtilidad y más ahermoseadamente lo hazen las lectiones historiales"

* Una versión preliminar de este artículo se presentó en el XI Congreso Español de Americanistas (AEA), celebrado en Murcia (7-10 de Septiembre de 2004).

1 Fernández de Oviedo, Gonzalo: Epílogo real, imperial y pontificial, Biblioteca Nacional de Madrid, ms. 6224, fol. 1, citado en Avalle-Arce, Juan Bautista: Introducción al Sumario de la natural historia de las Indias, Biblioteca Anaya, Salamanca, 1963, pág. 11. 
En los siglos XVI y XVII, la historiografía indiana experimentó una notable expansión. Numerosos tratados historiográficos se publicaron en Europa y alcanzaron una gran difusión. Uno de ellos, la Historia general y natural de Indias, Islas y Tierra Firme del Mar Océano (Sevilla: Juan Cromberger, 1535) de Gonzalo Fernández de Oviedo y Valdés, alias de Sobrepeña (1478-1557), recobra buena parte de su complejidad al ser analizada como un ejemplo de las praxis discursivas coloniales de la España imperial. ${ }^{2}$ Autores recientes insisten en que las crónicas en general, y la Historia General de Oviedo en particular, no hablan de una "realidad histórica" tal y como nosotros la concebimos. ${ }^{3}$ Son un conjunto de narraciones, relatos, estilos de contar las experiencias vividas en el Nuevo Mundo, impregnadas de providencialismo, mesianismo y de otros juicios de valor procedentes de su formación retórica y de la pastoral judeocristiana. ${ }^{4}$ Dentro de la narrativa americana de Oviedo existen dos géneros o tipos discursivos que influyeron decididamente en la construcción de su Historia. Dos procedimientos narrativos que evolucionaron en el transcurso del siglo XII y que se extendieron por toda España hasta alcanzar los territorios por ella conquistados: uno, literario, basado en el texto o narración - narratio o ars narrandi- que recupera y organiza los hechos pasados como parte de la composición de un género discursivo retórico (rerum gestarum), y otro, historiográfico, que busca explicar los hechos históricos en un sentido moderno; esto es, dar cuenta de las particularidades de los acontecimientos a través de la autoridad de lo "visto" y lo "vivido" (res gestae). ${ }^{5} \mathrm{El}$ "yo estuve allî" como poseedor de conocimientos de primera

2 Al respecto, véase Coello de la Rosa, Alexandre: De la Naturaleza y el Nuevo Mundo: Maravilla y Exoticismo en Gonzalo Fernández de Oviedo y Valdés. Fundación Universitaria Española, Madrid, 2002.

3 Recordemos que Oviedo es el primero que utiliza el término para designar la historia de la totalidad de las nuevas tierras descubiertas. O'Gorman, Edmundo: Sucesos y Diálogo de la Nueva España, Ediciones de la Universidad Nacional Autónoma de México, Imprenta Universitaria, México, 1946.

4 O’Gorman, Edmundo: Cuatro historiadores de Indias, Edit. SepDiana, México, 1979, pág. 67; Mendiola, Alfonso: Bernal Díaz del Castillo: verdad romanesca y verdad historiográfica, Universidad Iberoamericana, México, 1995; Ibidem: Retórica, comunicación y realidad. La construcción retórica de las batallas en la crónicas de la conquista, Universidad Iberoamericana, México, 2003, págs. 9-23.

5 Kohut, Karl: "La conquista en la crítica literaria", en Kohut, K. (ed.): De conquistadores y conquistados. Realidad, justificación, representación, Vervuert Verlag —Frankfurt am Main, 1992, pp. 30-34. Uno de los primeros en sistematizar esta "realidad objetiva" que llamamos historia fue Hegel, Georg: Lecciones sobre la filosofía de la historia universal, Revista de Occidente, Madrid, 1974, pág. 137. 
mano evoca una presencia participatoria, un contacto sensitivo con el mundo americano, una tangibilidad de percepción que se corresponde con los acontecimientos del presente americano. También sugiere un conocimiento acumulativo, enciclopédico, que favorecía la revisión y el cuestionamiento de enunciados anteriores, abriendo la posibilidad de añadir nuevos conocimientos.

La unidad de estos procedimientos o grupos narrativos depende de una serie de principios reguladores que definen y delimitan una formación discursiva (e.g., la historiografía de mediados del siglo XVI) sobre la base de lo que Walter D. Mignolo ha definido como metatexto. O lo que es lo mismo, el "medio" a través del cual una disciplina (e.g., la historia, la literatura) controla la producción de discursos (texto, narración) y el dominio de objetos (e.g., el contenido del texto en cuestión). ${ }^{6}$ Pero no debemos olvidar que la experiencia es una relación entre la "realidad-objeto" y el que la describe. De esta manera, pensamos que aunque la crónica ovetense contiene ciertos rasgos de estilo propios de un género cuyo carácter tiene que ver indudablemente con la historiografía ${ }^{7}$, incorpora múltiples planos alegóricos e imaginativos pertenecientes a una formación textual literaria. Negar la narratividad del discurso historiográfico conlleva olvidar el amplio sentido ideográfico que contienen las crónicas y relaciones del descubrimiento y la conquista del Nuevo Mundo. ${ }^{8}$ A continuación analizaremos el papel que juega el héroe cristiano y su reverso, el villano, como figuras literarias en la elaboración de la historiografía colonial e imperialista de Gonzalo Fernández de Oviedo.

6 Mignolo, Walter D.: “El Metatexto Historiográfico y la Historiografía Indiana”. Modern Languages Notes, Chicago, Vol. 96, págs. 358-402.

7 Como apunta Mignolo, a lo largo del siglo XVI los vocablos crónica e historia se convirtieron prácticamente en sinónimos (1981, pág. 375). Por el contrario, Alberto M. Salas considera que Oviedo no era un historiador, sino un cronista, porque el orden y la sistematización no son los factores dominantes en la Historia. Salas, Alberto: Tres Cronistas de Indias, Fondo de Cultura Económica, México, [1959] 1986, págs. 112-114).

8 Echevarría ha destacado el indiscutible valor literario de los primeros textos coloniales. González Echevarría, Roberto: Isla a su vuelo fugitiva. Ensayos críticos sobre literatura hispanoamericana, Madrid: José Porrua Turanzas, 1983, págs. 13-15). Para una lectura de Oviedo como autor de ficciones, véase Pupo-Walker, Enrique: La vocación literaria del pensamiento histórico en América. Desarrollo de la prosa de ficción: siglos XVI, XVII, XVIII y XIX, Editorial Gredos, Madrid, 1982, pág. 24. En la misma línea argumentativa, Arrom, señala que Oviedo es uno de los precursores de la narrativa hispanoamericana. Arrom, José Juan: "Gonzalo Fernández de Oviedo, Relator de Episodios y Narrador de Naufragios". Ideologies and Literature. Institute for the Study of Ideologies and Literature, Tomo 4, n. ${ }^{\circ}$ 17, Minneapolis, 1983, págs. 369-383. 
Ida Rodríguez Prampolini (1948) y Irving A. Leonard (1949) estudiaron algunas de las formas narrativas más utilizadas para organizar el texto historiográfico en los albores de la modernidad. El mundo caballeresco de la nobleza, con los ideales de lealtad al rey, la defensa de los débiles y de la cristiandad, la honra y la fama, se difundió a raíz del impacto de las novelas de caballería en la mente de los descubridores y conquistadores del siglo XVI. ${ }^{9}$ Era tan poco lo que se conocía del Nuevo Mundo que muchos cronistas e historiadores creyeron en aquéllos que decían haber visto ríos de oro, cíclopes, cinocéfalos, grifos, blemmyas o ewaipanomas, sirenas, amazonas y toda clase de seres fantásticos en los nuevos territorios. ${ }^{10} \mathrm{Y}$ no sólo eso, sino que ayudaron a la construcción de nuevos relatos prodigiosos y ficciones, los cuales sirvieron como modelos para nuevas conquistas-y también, para nuevas cosmografías fabulosas. ${ }^{11}$ Mito e historia, realidad y ficción se entremezclaron en las mentes y en los destinos de los nuevos conquistadores. La simbiosis del Viejo Mundo con la nueva Quarta Orbis Pars. ${ }^{12}$ América aparecía, así, como una realidad observada, al mismo tiempo, con espanto y fascinación; como un campo de acción y de desplaza-

9 Sobre el notable auge del género caballeresco en España y las novelas de caballerías que entraban en América, véase Rodríguez Prampolini, I.: Amadises de América. La hazaña de indias como empresa caballeresca, Junta Mexicana de Investigaciones Históricas, México, 1948 y Leonard, Irving A.: Books of the Brave, Cambridge University Press, Cambridge, Massachussets: 1949 (reimpresión en 1964), págs. 13-14.

10 Teniendo como referencia a Marco Polo, el primero en situar a las amazonas en tierras americanas fue Colón. En el diario de su primer viaje, el Almirante comenta que vivían en la isla de Matinino, ubicada en las Antillas. Pastor Bodmer, Beatriz: The Armature of Conquest. Spanish Accounts of the Discovery of America, 1492-1589, Stanford University Press, Stanford [1983] 1992, pág. 156. d'Anghiera (1457-1526) a menudo desmintió las apreciaciones del genovés. A pesar de ello, sus escritos reflejan la existencia de una isla llamada Madanina habitada por mujeres, pero no le dio demasiado crédito. Así, "se ha creído que los caníbales se acercan a aquellas mujeres en ciertos tiempos del año, del mismo modo que los robustos tracios pasaban a ver a las amazonas de Lesbos, según refieren los antiguos, y que de igual manera ellas les envían los hijos destetados a sus padres, reteniendo consigo a las hembras (...) d'Anguiera, Pietro Martire: Décadas del Nuevo Mundo, Primera Década, Libro II, Cap. III, Bajel Editor, Buenos Aires [1530] 1944, págs. 17.

11 A menudo los gobernadores inventaban conquistas a territorios lejanos para desembarazarse de toda clase de indeseables. Ello ayudó a difundir viejas leyendas. Sin ir más lejos, el mito de El Dorado empezó a difundirse alrededor de 1534, pero la versión definitiva se tejió alrededor de 1538 , Gandía, Enrique de: Historia crítica de los mitos de la conquista americana, Buenos Aires, 1929, citado en Pastor: The Armature of Conquest..., pág. 160.

12 He tomado prestado el concepto de Hernández Sánchez-Barba, Mario: La monarquía española y América. Un destino histórico común, Edit. Rialp, Madrid, 1990, pág. 22. 
miento para la geografía caballeresca. ${ }^{13}$ Pero, por encima de todo, la realidad americana fue contemplada a través de una prosa narrativa que tenía su razón de ser en una voluntad común de incorporarse en la historia a través de un nuevo sistema de valores y de las experiencias vitales de sus autores. ${ }^{14}$

Muchas de las crónicas, relaciones e informes se escribieron por autodidactas cuyos esquemas mentales pertenecientes al pensamiento tardo medieval y renacentista les sirvieron para ordenar el espacio natural y humano del Nuevo Mundo a través del prisma del hombre cortesano del siglo XVI español. La mayoría de ellas, como por ejemplo las Cartas de Relación de Hernán Cortés (1519-1526), la Historia General de las Indias (1569) de Francisco López de Gomara, o la Historia (Libro XXXIII) de Gonzalo Fernández de Oviedo, registraron en lengua vernacular las hazañas y los hechos memorables de los españoles en la Nueva España, alcanzando una gran difusión entre la audiencia europea de los siglos XVI y XVII. ${ }^{15}$ Las argumentadas críticas que los frailes dominicos plantearon a los excesos de la conquista fueron substituidas por una literatura épica de héroes cristianos que luchaban denodadamente por derrotar a imperios paganos. Una misma idea guiaba sus actos: alcanzar fortuna, gloria y algún tipo de promoción social. Aun cuando el propósito que movía a Oviedo era educar moralmente a una comunidad de lectores, aquellas proezas revelaron múltiples manipulaciones, adaptaciones y actualizaciones realizadas por una historiografía institucional al servicio de una idea de monarquía universal: la universitas christiana.${ }^{16}$ En efecto, la propensión de aquellos

13 Para Beatriz Fernández Herrero, América aparecía como una "ampliación utópica del espacio real europeo". Fernández Herrero, Beatriz: La utopía de América. Teoría. Leyes. Experimentos, Edit. Anthropos, n. ${ }^{\circ}$ 63, Barcelona, 1992, pág. 91.

14 Pupo Walker: La vocación literaria..., págs. 43; Pastor: The Armature of Conquest..., págs. 1-5.

15 En 1492, Elio Antonio de Nebrija (1441-1522) publicó la Gramática de la lengua castella$n a$, con la que recogió las normas y sistematizó las reglas de la lengua castellana. Pero no todos utilizaron el castellano como "la compañera del Imperio". Como señala López de Gomara, "(Pedro Mártir de Anglería) escribió muchas cosas de las Indias en latín, pues era cronista de los Reyes Católicos; algunos quisieran más que las escribiera en romance, o mejor y más claro. Todavía le debemos y loamos mucho, que fue el primero en las poner en estilo". López de Gomara, Historia, [Zaragoza, 1552] 1979, Cap. XLVIII, pág. 71.

16 Fernández de Oviedo, G.: Historia General y Natural de las Indias, Madrid: Biblioteca de Autores Españoles, Tomo 117, Libro VI, Cap. VIII, 1959, pág. 157. El nacionalismo etnocéntrico de Oviedo compartía gran parte del exaltado cesarismo de Dante Alighieri sobre el translatio imperii expresadas directamente en libro II de su De Monarchia y menos directamente en la La Divina Comedia (1307) y en el Convivio (1304-1308). Los trabajos de Dante se convirtieron en la ideología política del canciller imperial, el piamontés Mercurino Arborio, Marqués de Gattinara (1465-1530), formado entre las filas de funcionarios del Franco Condado, sobre todo por las influencias gibelinas que aspiraban a convertir a Carlos $\mathrm{V}$ en el único monarca del mundo, en un segundo Carlomagno. Menéndez Pidal, Ramón: Idea imperial de Carlos V, Edit. Espasa-Calpe, Madrid: 1940, pág. 11. 
cronistas a instrumentalizar la historia con fines pragmáticos no ocultaba, como bien señalaron E. Pupo Walker ${ }^{17}$ y J. J. Arrom ${ }^{18}$, la tendencia de Oviedo a mezclar la historia con la ficción y la política.

La elaboración de una crónica formaba parte del deber de funcionario de la monarquía española. En 1532 Fernández de Oviedo fue nombrado Cronista Real y tres años después publicó la primera parte de su Historia en la que describió la naturaleza y el paisaje del Nuevo Mundo en términos esencialistas. Pero también se sintió autorizado a inventar mitologías como la mejor manera de legitimar y expandir el imperio universal de su patrón, Carlos V, al Nuevo Mundo. ${ }^{19}$ De acuerdo con las tesis de Ginés de Sepúlveda, la naturaleza corrupta de los amerindios — servi a natura - justificaba por sí misma la conquista. Pero Oviedo no se conformó solamente con repetir aquel viejo argumento de la barbarie de los indios y los derechos de la conquista. Hizo mucho más. Sostuvo que los habitantes del Nuevo Mundo eran en realidad los descendientes de una diáspora visigoda, con lo cual redujo la singularidad del descubrimiento de Cristóbal Colón (1451-1506) y las donaciones pontificias a un segundo nivel. No se trataba del des-cubrimiento de un continente, sino del hallazgo no premeditado de unas islas lejanas, fabulosas, para la antigüedad mediterránea - las legendarias Hespéridas, o Hespéride - que tomaban su nombre del rey Hespero XII, un antiguo rey de España que las había mandado descubrir más de tres mil años antes. Como apunta Oviedo,

“(...) agora tres mil é ciento é noventa é tres años, España é su rey Hespero, señoreaban estas islas o Indias Hespérides; é assi con derecho tan antiquíssimo é por forma que está dicho, ó por la que adelante se dirá en la prosecución de los viajes del Almirante Cristóbal Colón, volvió este señorío a España a cabo de tantos siglos. E paresce que, como cosa que fue suya, quiere la divina justicia que lo haya tornado á ser é lo sea perpetuamente" ${ }^{20}$

17 Pupo-Walker: La vocación literaria..., págs. 38 y ss.

18 Arrom: "Gonzalo Fernández de Oviedo...", pág. 134.

19 Mi entendimiento del imperialismo español reconoce las dos dimensiones de la herencia romana: la idea de imperium como soberanía e imperium como gobierno sobre múltiples dominios, federaciones o reinos bajo un único monarca legislativo. Elliott, John H.: "A Europe of Composite Monarchies". Past and Present, CXXXVII, Oxford, 1992, págs. 48-71; Pagden, Anthony: Lords of All the World. Ideologies of Empire in Spain, Britain and France c. 1500-c.1800, Yale University Press, New Haven \& London, 1995, pág. 16.

20 Fernández de Oviedo, Historia..., Tomo 117, Libro II, Capítulo XIII, 1959, pág. 50. Véase también Historia, Tomo 118, 1959, pág. 86 (Proemio al Libro XVI). Alrededor de 1548, una vez solucionado el conflicto con los herederos de Colón, el cronista Pedro de Medina (1493-1567) localizó las Hespérides mucho más cerca: en las Islas Canarias (Libro de grandezas y cosas memorables de España, en Obras de Pedro de Medina, editadas por Ángel González Palencia, CSIC, Madrid, 1944, pág. 68). 
Fue el propio Dios, dice Oviedo, quien hizo volver el señorío de La Española y las islas de Barlovento a España a través del primer Almirante, proporcionando un argumento formidable que, en esencia, cuestionaba la legitimidad de los herederos de Cristóbal Colón para reclamar cualquier derecho en los territorios recién descubiertos de Tierra Firme. No era lo mismo dominar unas tierras que Colón había cedido a los reyes castellanos que reincorporar a la soberanía de España algo que antaño fue suyo. ${ }^{21} \mathrm{La}$ cuestión es saber determinar los nexos entre la "verdad histórica" que corresponde al conocimiento historiográfico, y las estrategias retóricas de representación -interpolaciones, cuentos, leyendas, anécdotas sencillas, ejemplos, simples parodias, retratos de personas, etc. - creados por ella.

Esta es, sin duda, una tarea ardua. Numerosos investigadores del período colonial han señalado que los cronistas indianos - Oviedo, Las Casas, López de Gomara- reclamaron el carácter utilitario de la "Historia General" y se esforzaron en evitar la verosimilitud, que correspondería no a la historia sino a la poética y a la oratoria. Rechazaron la "realidad maravillosa" de los libros de caballerías porque representaban acciones que eran del todo inconsecuentes con las posibilidades de la acción humana en una sociedad estratificada, y en su lugar, abogaron por un conocimiento más honesto y ejemplar ajeno a los bestiarios medievales y a la fábula, que es, recordemos, el alma de la Poética. ${ }^{22}$ Ello potenció la aparición de un nuevo

21 Bataillon, Marcel: "Historiografía oficial de Colón. De Pedro Mártir a Oviedo y Gomara". Imago Mundi. Revista de Historia de la Cultura, Tomo 5, Buenos Aires, Septiembre de 1954, págs. $23-$ 39; Arranz Márquez, Luís: Introducción a la Historia del Almirante, de Hernando Colón, Historia 16, Madrid, [1539] 1991, pág. 24. Oviedo sostuvo esta tesis en el Catálogo Real de Castilla (1532, ff. 19r) y en numerosos pasajes de la Historia, Tomo 117, Libro II, Capítulo XIII, 1959, pág. 50. Véase también el Tomo 118, 1959, pág. 86 (Proemio al Libro XVI). En su Historia del Almirante, Hernando Colón rechazó semejante tesis por considerarla falsa (Historia del Almirante, Historia 16, Madrid [1539] 1991, págs. 76-83). Gomara también la rechazó, apuntando que las Indias no eran las Hespérides, sino las islas de Cabo Verde y las Gorgonas. López de Gomara, F.: Historia General de las Indias y vida de Hernán Cortés, Biblioteca Ayacucho, n. ${ }^{\circ}$ 64, Caracas, 1979, Cap. CCXXI, pág. 314). Después de muchos pleitos, el hijo de Diego Colón, Luís, primer duque de Veragua y Tercer Almirante de las Indias, aceptó un compromiso en 1536 para poner punto final a las acciones legales contra la Corona española. Renunció a las dignidades de virrey y de gobernador, concedidas a su abuelo Cristóbal Colón el 28 de Mayo de 1493, y confirmadas en 1497, a favor de la Corona. A cambio conservó el título honorífico - - y hereditario— de Almirante (Bataillon: "Historiografía oficial de Colón...", págs. 23-39; Gerbi, Antonello: Nature in the New World. From Christopher Columbus to Gonzalo Fernández de Oviedo, University of Pittsburgh Press, Pittsburgh [1975] 1985, pág. 155).

22 La Poética de Aristóteles no se tradujo al castellano hasta 1626 (La Poética, dada a nuestra lengua castellana por don Alonso das Seyjas y Tobar, Madrid, 1626). Anteriormente circulaba en España y fuera de ella gracias a los comentarios de Francesco Robortelli, In Librum Aristotelis de Arte Poetica explicationes (Florencia, 1548), y Alonso López Pinciano, La Filosofía antigua poética (Madrid, 1593). 
saber basado en la experiencia personal directa y en unos criterios de verdad historiográficos que obligaban a corregir y ampliar el conocimiento (oral) previo sobre el mundo. ${ }^{23}$ Este último punto es importante porque la inclusión de nuevos conocimientos, ya se trate de la cosmografía o del arte de la navegación, de la historia natural o la política, no implicó un rechazo de los modelos clásicos, en especial la metafísica aristotélica y la filosofía moral, sino que aumentó el espacio de lo decible y lo pensable ${ }^{24}$. Oviedo creía efectivamente que las Etimologías de Isidoro, la Historia de las Plantas de Teofrasto, la Geografía de Ptolomeo (150 AC), y especialmente, teniendo la Historia Natural de su tan admirado Plínio Segundo (23-79 DC) — también conocido como Plínio el Viejo- eran una herramienta excelente y un modelo a imitar para configurar la idea del Nuevo Mundo. ${ }^{25}$ De acuerdo con la sabiduría heredada de estos Antiguos (la reiteración de "lo ya dicho, escrito o sabido"), pero sin ser prisionero de ellos, Oviedo llevó a cabo el primer intento serio de clasificar y subordinar los nuevos territorios como una panoplia de mundos exóticos. ${ }^{26}$ Pero tanto la historia natural como la historia moral utilizaron numerosos recursos alegóricos y metafóricos que confirman la inclinación imaginativa del texto y la vocación de narrador que poseía Oviedo.

23 Mignolo: "El Metatexto Historiográfico...”, pág. 387; Bénat-Tachot, Louise: "La experiencia en el proceso cognitivo de las sociedades indígenas en la Historia general y natural de las Indias de Fernández de Oviedo", en Kohut, K. \& Rose, Sonia V. (eds.): Pensamiento europeo y cultura colonial, Iberoamericana Vervuert Verlag, Madrid, 1997, págs. 247-261.

24 La mayoría de historiadores reconocían la superioridad de la experiencia ocular para registrar los hechos históricos. El mismo López de Gomara, quien nunca visitó el Nuevo Mundo, apuntaba que "la experiencia, que nos certifica por entero de cuanto hay, es tanta y tan continua en navegar el mar y andar la tierra, que sabemos cómo es habitable toda la tierra, y cómo está habitada y llena de gente", López de Gomara, F.: Historia, [Zaragoza, 1552] 1979, Cap. III, pág. 14.

25 Fernández de Oviedo, Historia, Tomo 117 (Proemio, Libro II), 1959, pp. 13. Sobre la relación entre Plínio y Oviedo, véase el trabajo de Álvarez López, Enrique: "Plínio y Fernández de Oviedo". Anales de Ciencias Naturales del Instituto José de Acosta, Tomo I, Madrid, 1940, pp. 40-61; Tomo II, Madrid, 1941, págs. 1-23. Véase también la discusión que hace Stephanie Merrim sobre el uso de Plínio en "The Aprehension of the New in Nature and Culture", en René Jara \& Nicholas Spadaccini (eds.), 1492-1992: Re/Discovering Colonial Writing, Hispanic Issues, Tomo 4, The Prisma Institute, 1989, págs. 174-175.

26 Kohut: "La conquista...”, pp. 43-44; Bénat-Tachot, Louise: "L’Antiquité: obstacle ou auxiliaire pour la description du Noveau Monde", en Bénat-Tachot, L. \& Gruzinski, Serge: Passeurs Culturels. Mécanismes de métissage, Presses Universitaires de Marre-la-Vallée, Editions de la Maison des sciences de l'homme, París, 2001, págs. 229. 


\section{II}

Una de las razones que contribuyen a explicar estas variaciones en el canon narrativo ovetense tiene mucho que ver con su estancia en la Italia de principios del siglo XVI. El discurso expositivo de la historiografía humanista italiana, de la cual Oviedo era un buen conocedor, consideraba que la historicidad de la narración debía corresponder con una obvia calidad literaria. Hasta ese momento los anales, relaciones o crónicas medievales eran definidos por la parquedad de estilo. Sus descripciones pretendían únicamente ensalzar las gestas de los monarcas y caballeros "principales" cuyo papel era clave en el mantenimiento y conservación del orden feudal (e.g., la Crónica de Alfonso XI, la Crónica de los Veinte Reyes, la Crónica de los Reyes de Castilla (Siglo XIV). Con el advenimiento del Quattrocento italiano, algunos poetas e historiadores humanistas, como los florentinos Poggio Bracciolini (1380-1459), Ange Politien (1454-1494), Leonardo Bruni (1370-1444) y el napolitano Lorenzo Valla (1407-1457), entre otros, redefinieron sus propósitos morales, intelectuales y estéticos, así como las técnicas mediante las cuales podían expresarse correctamente. Para ello elaboraron una narración histórica caracterizada por mantener un alto nivel de expresividad, elocuencia y elegancia expositiva en los acontecimientos narrados. Para muestra un botón. Destacados humanistas italianos, como el milanés Pietro Martire de Anghiera (traído de Milán a España en 1487 por el Conde de Tendilla y nombrado "Maestro de los caballeros de la Corte en las Artes Literarias"), aseguraba a su ilustre lector, el Papa León X (1513-1521), a quién también había dedicado su Segunda Década, que de las muchas cosas que cada informante le contó sobre el descubrimiento de Vasco Núñez de Balboa del Mar del Sur (Noviembre, 1513), pasando por alto las que no eran dignas de mención, él seleccionó únicamente lo que le pareció que había de satisfacer a los amantes de la historia. ${ }^{27}$

Para nuestro propósito, el sumario de Pietro Martire sobre el descubrimiento de Balboa ilustra la idea de que la narrativa histórica dependía de una coherencia estructural propia de la narración. Se buscaba un equilibrio entre la información y la forma más adecuada para transmitirla. ${ }^{28}$ Ello favo-

27 Martire d'Anghiera, Pietro: Décadas del Nuevo Mundo, Segunda Década, Libro VII, Capítulo I, Tomo I, [Alcalá de Henares, 1516] 1944, pág. 168.

28 Pupo-Walker: "El Metatexto Historiográfico...", págs. 80-92. 
reció la creación de una clase de textos — historias, biografías, epopeyas elaboradas a partir de anécdotas, sucesos simplificados, arrancados del contexto inmediato para ser interpretados en la reconstrucción (histórica) posterior-que dieron lugar a "otros" mundos significativos. Para Oviedo, las coordenadas del pensamiento histórico debían girar necesariamente en torno a la obligación de informar sobre lo que se consideraba "verdadero". A diferencia de los libros de caballería, que no servían para nada, la historia debía tener una finalidad práctica, útil a la Corona y al gobierno de las Indias. ${ }^{29}$ Por esta razón en la primera parte de su Historia se negaba a dar crédito a numerosas fábulas atlantistas y leyendas sin fundamento, como por ejemplo la isla Perdida de San Anselmo, las Siete Ciudades de Cibola y la Antillía, la Atlántida, la Fuente de la Eterna Juventud, San Borondón, el país de la Canela, Jauja, El Dorado, etc. ${ }^{30}$ El rigor de la nueva historiografía le llevó a criticar, entre otros, a Pietro Martire de Anghiera y Francisco López de Gomara, acusándolos de no haber estado nunca en Indias y de representar una historiografía erudita que falsificaba la realidad al difundir un espacio geográfico positivo e hiperbólico. ${ }^{31}$ Pero Oviedo no siempre era testigo de todo lo que narraba, especialmente en la segunda y terceras partes, y a menudo utilizó determinadas fantasías históricas, difícilmente verosímiles, insertándolas en la Historia General. ${ }^{32}$ Sin ir más lejos, los indios gigantes "de doce o trece palmos de alto" que la expedición de Fernão de Magalhaes encontró en el Puerto Deseado o bahía de San Julián (Libro XX), o "la funesta estirpe de las mujeres amazonas", que Hesíodo situaba fuera de las normas de la polis griega (Teogonía, 588-591), y que en este caso, vivían junto al río Papomene, en el golfo de Venezuela (Libro XXV, Cap. XIV), certificaban una cultura "patagona" y "amazona" dentro de las cuales los lectores podían reubicar funcionalmente los textos historiográficos ovetenses.

29 Kohut: "La conquista...”, pág. 39.

30 Coello de la Rosa, Alexandre: "De héroes y villanos. La sublevación de los indios de San Juan de Puerto Rico (1511) en el libro XVI de la Historia General y Natural de las Indias de Gonzalo Fernández de Oviedo y Valdés", en Dalla Corte, Gabriela, García Jordán, Pilar, Izard, Miquel, Laviña, Javier, Piqueras, Ricardo, Ruiz Peinado, José Luís y Tous, Meritxell: Relaciones sociales e identidades en América, Publicacions de la Universitat de Barcelona, Barcelona, 2004, pp.252-254.

31 Salas: Tres cronistas..., págs. 105-106.

32 Gil, Juan: Mitos y utopías del descubrimiento, Tomo II, El Pacífico, Alianza Editorial, Madrid, 1989. 


\section{III}

Oviedo introduce aquí un elemento que se ajusta a esta mistificación de la realidad americana: siendo hombres y mujeres extraordinarias, sus oponentes (españoles) tenían que ser capaces también de realizar acciones superlativas. Siguiendo este razonamiento, uno de los recursos narrativos utilizados por el cronista fue la utilización de patrones arquetípicos de la tradición clásica y cristiana del Medioevo a la hora de representar la figura del héroe cristiano en el Nuevo Mundo. Esencialmente se trataba de construir un modelo simbólico para poder expresar sus ideas de forma universal y llegar con más fuerza a sus lectores. Al hacerlo, el autor descubre el carácter comunicativo de la Historia, cuyos enunciados dependen del horizonte de expectativas de dichos interlocutores. ${ }^{33}$ También revelaba su verdadera intención: construir un modelo de descubridor que reproduce un ideal heroico de comportamiento en una sociedad posibilista pero estructurada jerárquicamente. Para ello Oviedo hizo uso de unas estructuras discursivas —narración, descripciones-que trascendía las restricciones impuestas por el marco histórico. En ellas, el cronista madrileño puso al descubierto una serie de procedimientos retóricos que traducirán la experiencia americana a una forma textual armónica y efectiva. Este proceso escritural está íntimamente afectado por la acción de múltiples subjetividades y constricciones políticas que objetivaba la crónica como un fenómeno literario y comunicativo entre el autor y su audiencia. ${ }^{34}$ Analizar la construcción del héroe cristiano por parte de Oviedo requiere, pues, un estudio de los diversos modelos de héroe que aparecen en la morfología de su Historia.

En primer lugar encontramos el héroe militar, encarnado en las figuras de Ponce de León, Hernán Cortés, Diego de Almagro o Gonzalo Jiménez de Quesada, poseedores, entre otros, de los vicios y las virtudes de aquellos héroes ejemplares de la Grecia clásica.

La Edad de los Héroes griegos mostraba la supremacía de una clase de hombres de primera categoría muy superiores a los mortales. Sirvan de modelo de referencia los elogios a un Cortés arquetípico, quien, a juicio de

33 Para una teoría constructivista y hermenéutica de la recepción de las crónicas, véase Mendiola: Retórica..., págs. 12-13. Sobre esta mediación entre el texto historiográfico ovetense y la audiencia, véase también Kohut: "La conquista...”, págs. 42-44.

34 Mendiola: Retórica..., págs. 18-19. 
Oviedo, llevó tan alto como nadie el valor militar y el sentido político de sus acciones. Sus hazañas militares representan la culminación de las expediciones anteriores (Francisco Hernández de Córdoba, Cristóbal de Morante y Lope Ochoa de Caicedo, 1516; Juan de Grijalva, 1518) y se equiparaban a las de Julio César, Viriato y Alejandro de Macedonia, que aspiraba a ser un nuevo Aquiles. ${ }^{35}$ Destacar también las tribulaciones de uno de los supervivientes de la expedición frustrada a la Florida que dirigió Pánfilo de Narváez (1527), de nombre Alvar Núñez Cabeza de Vaca, quien después de naufragar en la bahía de Tampa, volvió a encontrar a los suyos en la Nueva Galicia, al norte de México, después de ocho años de vida nómada entre los indios de las llanuras ${ }^{36}$, o los viajes y trabajos del Adelantado Diego de Almagro en su expansión hacia Chile y su vuelta al Perú $^{37}$, los cuales sobrepasaron con mucho a los de Ulises, Jasón y Hércules. O las entradas efectuadas desde Santa Marta por "la diligencia y buena maña de su general" Gonzalo Jiménez de Quesada en busca de El Dorado, que le llevaron a descubrir a los orfebres chibchas en el valle del Cauca y en la meseta de Bogotá en 1538. ${ }^{38}$ En aquel Nuevo Reino de Granada se enfrentó a muchos indios, en especial a las mujeres guerreras de la reina y soberana Jarativa, lo que recordaba los combates llevados a cabo por el mismo Hércules en lucha contra las Amazonas en las márgenes del Termodonte. ${ }^{39} \mathrm{Y}$ al igual que Jasón, a quien su tío Pelías envió al lejano país de la Cólquide a buscar el Vellocino de Oro si quería ejercer como legítimo soberano de Yolcos, Juan Sebastián Elcano regresó a su lugar de origen como la encarnación del héroe tesalio, como es sabido, doblando el cabo de Buena Esperanza y llegando cuatro meses después al Puerto de Santa María, tras recorrer 14.000 leguas con tan sólo 18 hombres y la nave

35 Para un ejemplo de la construcción de la figura de Cortés como héroe mítico, véase el excelente trabajo de Pastor: The Armature of Conquest..., págs. 50-100.

36 Fernández de Oviedo, Historia, Libro XXXIII, Cap. III, 1959, pág. 299.

37 Ibidem: Historia, Libro XLVII, Cap. I-VI, 1959, págs. 124-151.

38 Ibidem: Historia, Libro XXVI, Cap. XXX, 1959, págs. 124-128.

39 Ibidem: Historia, Libro XXVI, Cap. XXIX, 1959, págs. 124. Oviedo se resistía a creer en la existencia de unos seres salvajes que, como las amazonas, combinaban rasgos femeninos con elementos notoriamente masculinos, como su amor por las armas y la guerra. Según el testimonio de Jiménez de Quesada, las amazonas vivían en el río Grande de Sancta Marta en el Valle de Bogotá y que mantenían "comunicación y conversaçión carnal" con sus esclavos. Ibidem: Historia, Tomo 119, Libro XXVI, Cap. XI, 1959, pág. 87, Cap. XXIX, pág. 123. Sobre las amazonas, véanse, entre otros, los trabajos de Blake Tyrrell, William: Las amazonas. Un estudio de los mitos atenienses, Fondo de Cultura Económica, México, 1989; Gerbi: Nature in the New World..., [1975] 1985; e Leonard, I. A.: "Conquerors and Amazons in Mexico". Hispanic American Historical Review, XXIV, Durham, NC, 4 (1944), págs. 561-579. 
Victoria, la única de las cinco que quedaba, cargada de especias. ${ }^{40}$ Todas estas historias reproducen los sufrimientos y penalidades de unos seres liminares de vida arriesgada que se situaban a caballo entre los dioses y los hombres. Algunas, incluso, como las hazañas que cantan los poemas homéricos (Ilíada, Juan de Mena, 1519; Odisea, Salamanca, 1550), eran vividas por el público como un acontecimiento real, perteneciente al mismo orden temporal del poeta elegíaco y su auditorio. ${ }^{41}$

Del mismo modo, muchos de aquellos personajes reproducían un ideal caballeresco característico de la historiografía cristiana (Amadís de Gaula, Claribalte, Tirant lo Blanc, Palmerín de Olivia) y de la Antigüedad clásica (Hércules, Jasón, Ulises). ${ }^{42}$ Se trata de la construcción mítica del conquistador como un héroe militar en lucha contra el infiel - judío, "moro", indio- cuya ejemplaridad radica en su destreza en el manejo de las armas y su capacidad política de liderazgo. Son grandes hombres infanzones, caballeros, hidalgos - dotados de todas las virtudes -el sentido del honor, la audacia, coraje y valentía en los campos de batalla, fidelidad al monarca - y los defectos - la mayoría se rebelaron contra sus jefes legítimos- de los héroes españoles de los tiempos antiguos, como el Cid Campeador, Bernardo del Carpio o Viriato, que lucharon valerosamente contra enemigos paganos muy superiores en número. Este impulso militar, este afán adoctrinador se remontaba históricamente a los inicios de la Reconquista, esgrimiendo sus mismos valores ético-militares, su mismo ideario de un universalismo represivo y su misma racionalidad. ${ }^{43}$ La historicidad y el realismo de la épica medieval castellana trasladarán aquella épica de conquista contra los musulmanes, tan frecuente en las novelas de caballerías, a ese Nuevo Mundo que los hidalgos españoles imaginaban como una tierra de promisión. Ello podría parecer contradictorio, teniendo

40 Dedicatoria a la Segunda Parte de la General Historia de las Indias, Volumen 118, 1959, pág. 213.

41 García Gual, Carlos: Mitos, viajes, héroes, Editorial Taurus, Madrid, 1981.

42 La tradición legal castellana, por medio de las Las Siete Partidas, redactadas entre 1256 y 1263 y promulgadas en 1348 por Alfonso X el Sabio, certificó las cualidades que debía tener un caballero ideal. Segunda Partida, Título XXI, Ley VIII, "Como deven los caualleros ser arteros e mañosos", en Las siete partidas del Sabio rey don Alfonso el nono, Andrea Portonariz, Salamanca, 1555.

43 Al respecto, Fernández de Oviedo señalaba que "no contentándose aquellos sanctos príncipes (los Reyes Católicos) con sola su empresa e conquista santísima que entre las manos tenían, con que dieron fin a la subjeción de todos los moros de las Españas (...); pero, demás de reducir a España toda a nuestra católica religión, propusieron de enviar a buscar ese otro Nuevo Mundo, a plantarla en él, por no vacar ninguna hora en el servicio de Dios.” Fernández de Oviedo: Historia, Tomo 117, Libro II, Cap. IV, 1959, pág. 22. 
en cuenta que Oviedo, a pesar de haber escrito él mismo un libro de caballerías, había denostado públicamente esa "antigua afición". ${ }^{44}$ Pero, como acertadamente señaló el crítico L. Emilfork, a pesar de sus intentos por ceñirse a la "historia verdadera", la medida de lo grandioso seguía siendo lo fabuloso. Las acciones españolas en el Nuevo Mundo fueron realmente portentosas, y para hacerlas verosímiles, Oviedo no tuvo más remedio que recurrir a lo "maravilloso". ${ }^{45}$

Desde una perspectiva literaria, K. A. Myers ha demostrado que la diseminación de estos textos híbridos constituye una parte importante en la Historia de Oviedo. ${ }^{46}$ J. J. Arrom y L. Bénat Tachot, por ejemplo, sostienen que la interpolación de unidades narrativas simples en forma de cuentos, pequeñas anécdotas, o leyendas pueden identificarse y disociarse perfectamente del resto de la narración. Son principalmente relaciones de sucesos cuya dimensión didáctica o moral abarca desde la tradición historiográfica romana —el exemplum — hasta la tradición española de historias y relatos cortos. La construcción de la narratio, a juicio de Bénat, sigue un orden expositivo que se inicia con una introducción, una cristalización de tensiones y un final. ${ }^{47}$ Una de esas narraciones autónomas e independientes es el episodio de Becerrillo y la india borinqueña donde, como apunta J.J. Arrom, el héroe es el perro. Un perro famoso por su agresividad hacia los indios y que al echarle una de las "viejas indias prisioneras", en lugar de devorarla, "alzó una pierna e la meó". ${ }^{48}$ El suceso es significativo porque sirve para transmitir una enseñanza moral en clave de humor al tiempo que amplifica una de las virtudes del héroe: la benevolencia. Si el héroe-perro

44 Nos estamos refiriendo al famoso Claribalte (Valencia, Juan Viñao, 1519; Sevilla, Andrés de Burgos, 1545). Alberto del Río Nogueras acaba de publicar una nueva edición (Centro de Estudios Cervantinos, Madrid, 2001). Para un estudio sistemático del Claribalte, véase el excelente trabajo de Merrim, S.: "The Castle of Discourse: Fernández de Oviedo's Don Claribalte (1519), or 'los correos andan más que los caballeros"'. Modern Languages Notes, Chicago, n. ${ }^{\circ}$ 97, 1982, págs. 329-346.

45 Emilfork Tobar, Leonidas: "La doble escritura americana de Oviedo". Revista Chilena de Literatura, Tomo 19, Santiago de Chile, Abril de 1982, págs. 21-38.

46 Myers, Kathleen A.: "History, Truth and Dialogue: Fernández de Oviedo's Historia general y natural de las Indias (Bk XXXIII, Ch LIV)”. Hispania, n. ${ }^{\circ}$ 73, Madrid, 1990, pág. 617.

47 Bénat Tachot, Louise: "El relato corto en la Historia general y natural de las Indias de Gonzalo Fernández de Oviedo", en Kohut, K. \& Rose, Sonia V. (eds.), La formación de la cultura Virreinal. I. La etapa inicial, Madrid -Frankfurt/Iberoamericana, 2000, págs. 104-107.

48 Arrom: "Gonzalo Fernández de Oviedo...", pág. 136. El mismo episodio lo comenta el Padre B. de Las Casas, pero con un objetivo diferente: demostrar que incluso las bestias podían ser menos crueles que los españoles. Ibidem: "Becerrillo: comentarios a un pasaje narrativo del padre Las Casas", en Homenaje a Luís Alberto Sánchez, Universidad de San Marcos, Lima-Perú, 1968, págs. 42-44. 
no le hizo "mayor mal", los cristianos eran clementes con sus enemigos, aunque muchos, dice Oviedo, lo tuvieron por "cosa de misterio". ${ }^{49}$

En segundo lugar, cabe destacar el heroísmo del descubridor, representado por las figuras de Cristóbal Colón, Fernão de Magalhaes y Juan Sebastián Elcano, que inaugura un modelo de héroe enfrentado a un mar desconocido y vacío. Se trata de avezados navegantes, valientes y arriesgados, profundamente religiosos, dotados de una extraordinaria confianza en sí mismos y en sus posibilidades. En este sentido, la soledad de Colón en el primer viaje, y luego, en la administración de la colonia, las tribulaciones del portugués Magalhaes desafiado por Juan de Cartagena y por el resto de sublevados en abril de 1520, o el viaje homérico que protagonizó Juan Sebastián Elcano entre 1519 y 1522 de vuelta a España evocan actitudes heroicas equivalentes a las experiencias de aquellos semi-dioses como Jasón. El interés por disuadir o burlar a los potenciales competidores en sus intereses comerciales a los mercados de América y Asia llevaron a los mismos navegantes reconvertidos en cronistas (Colón, Elcano, Pigafetta, etc.) a difundir narraciones imaginarias - historias de grandes riesgos, la existencia de monstruos marinos, terribles tribus, como los gigantes patagones, y toda clase de peligros - que revelan una relación comunicativa entre el autor y su audiencia. Es decir, el autor conoce los hechos, objetos y acontecimientos y los expone de acuerdo a las expectativas de una audiencia preparada para recibirlos. Así, muchas de las fábulas del repertorio mitológico que antaño se situaban en el contexto geográfico y cultural del Mediterráneo central, pasaron a ubicarse en las costas e islas del Atlántico. Las características del viaje eran tan terribles y de tan alto riesgo, que Colón, Vespucci, Magalhaes o Elcano compensaban las deficiencias técnicas, científicas y cartográficas de sus expediciones con una extraordinaria fe en el éxito de la empresa y en su fidelidad religiosa. Esas cualidades de buenos caballeros y vasallos los convertían en figuras más cercanas a la humanidad del lector.

49 Fernández de Oviedo, Historia, Libro XVI, Capítulo XI, 1959, págs. 104. El amo de Becerrillo era Sancho de Arango, quien, junto con Gregorio Páez, habían sido encomenderos en San Juan de a Maguana (La Española) y que en 1516 obtuvieron la representación de la isla de San Juan. Giménez, Manuel: "Política Indiana del Canciller Jean le Sauvage (8-11-1516-7-6-1517)". Anuario de Estudios Americanos, Tomo XII, Sevilla, 1955, pág. 172. El Adelantado Vasco Núñez de Balboa poseía un perro llamado Leoncillo, hijo del famoso Becerrillo, y dotado de las mismas habilidades que tenía su parte, y a veces dos, en el botín de guerra como cualquier hombre de guerra. Ambos recibían parte del botín y ganaron para sus amos mucho oro y esclavos. López de Gomara, Historia..., [Zaragoza, 1552] 1979, Cap. LXV, pág. 99. 
Pero la construcción del héroe ovetense conlleva su reverso. A lo largo de las páginas de la segunda parte de la Historia, Oviedo lamenta que los españoles estuvieran más interesados en el oro y las riquezas que en la defensa de los intereses de la Corona: "cosas han pasado en estas Indias en demanda de aqueste oro, que no puedo acordarme dellas sin espanto y mucha tristeza de mi corazón". ${ }^{50}$ Si bien en la primera parte de su Historia la naturaleza del Nuevo Mundo es la indiscutible protagonista, a partir de 1535 Oviedo se centrará en la decadencia del descubridor como modelo heroico, proporcionando unos relatos menos edificantes, más críticos, y por supuesto, mucho menos edénicos que los de la primera parte. Rebeliones, insurrecciones militares y traiciones ponen de manifiesto no sólo la inexistencia de aquel locus amoenus que maravilló a Cristóbal Colón entre 1492 y 1504, sino también la corrupción de una sociedad en crisis.

La exploración, conquista y explotación de las islas antillanas se lleva a cabo con gran rapidez. Pero desde el primer momento la destrucción de los "indios" se produjo de manera inexorable. El etnocidio cometido sobre la población arawak no se manifestaba solamente como uno de los episodios más crueles de la historia humana, sino sobre todo como un desastre colectivo de amplitud sin precedentes. Pero la constatación empírica y la difusión de este hecho no fue patrimonio exclusivo de Bartolomé de Las Casas (1484-1566) y de los frailes dominicos. ${ }^{51}$ Frente al canibalismo y la vida salvaje y desordenada de los bárbaros del Nuevo Mundo, el humanista francés Michel de Montaigne (1533-1592) opuso la traición, la tiranía y la crueldad de la que hicieron gala los españoles, que había diez-

50 Fernández de Oviedo, Historia, Libro XXV, Cap. VII, 1959, pág. 26.

51 El carácter criticista de la mayoría de los planteamientos de Las Casas y de muchos teólogos, misioneros e intelectuales contemporáneos suyos (Fray Antonio de Montesinos, Alonso de Veracruz, Domingo de Soto, etc.), inauguró el llamado movimiento indigenista, basado en la defensa del indio y en el rechazo de las llamadas guerras de conquista, así como de los sistemas de encomiendas (Las Casas, Juan Ramírez), la esclavitud, el régimen de las mitas. Abril Castelló, Vidal: "Bartolomé de Las Casas y la segunda generación de la Escuela de Salamanca". Revista de Filosofía, n. 2 (6), Madrid, 1983, págs. 5-19. El discurso argumentativo que elaboró Las Casas en la Historia de las Indias (1527-1559) y en la Apologética Historia Sumaria (1551), sintoniza con una actitud moderna respecto a la problemática indígena: los posicionamientos ideológicos y éticos de la antropología aplicada, así como su interés en las realidades sociales multiculturales. 
mado a la población amerindia. ${ }^{52}$ Oviedo ya había observado esta disminución como un fenómeno exponencial sin precedentes:

"Cansancio es, y no poco, escrebirlo yo y leerlo otros, y no bastaría papel ni tiempo a expresar enteramente lo que los capitanes hicieron para asolar los indios e robarlos e destruir la tierra, si todo se dijese tan puntualmente como se hizo; pero, pues dije de suso que en esta gobernación de Castilla del Oro había dos millones de indios, o eran incontables, es menester que se diga cómo se acabó tanta gente en tan poco tiempo" ${ }_{53}$

En la década de 1540 los objetivos parecen haber cambiado. Oviedo no se parece al desilusionado viajero que describía $\mathrm{Cl}$. Levi-Strauss en Tristes Trópicos (1955). Lo que le preocupa no es la desintegración del mundo caribeño a manos de la dominación colonial española, sino que dicha dominación aparece como un proceso de ruina y decadencia cultural. Algunos autores, como Beatriz Pastor, han hablado de un discurso narrativo de la desmitificación y el fracaso para dar cuenta de la aparición de una conciencia crítica en la valoración del proceso de conquista y colonización americanas. ${ }^{54}$ Pero la Historia no sitúa a los "buenos y malos españoles" en un orden cronológico. Aunque la segunda parte no abunda en héroes ni caballeros de espuelas doradas que defiendan el honor y la grandeza de la nación española, Oviedo los utiliza (e.g., Jiménez de Quesada) para contrastarlos con aquellos hombres ambiciosos interesados tan sólo por el poder del oro y de las piedras preciosas. Tras adjudicarse el rol de señores, algunos se convirtieron en miembros de un colectivo parasitario. Uno de ellos, el Justador Pedro Arias Dávila (Pedrarias), se convirtió en la némesis del cronista madrileño. Nada hay en él que recuerde al modelo heroico

52 El relativismo cultural de Montaigne quedó patente al aseverar que las costumbres cristianas no eran ni más ni menos racionales que las demás. En este sentido expuso que "hallo más barbarie en comer a un hombre vivo que en comerlo muerto. Y sabemos, no sólo por haberlo leído, sino visto ha poco (y no entre enemigos antiguos, sino entre vecinos y conciudadanos y so pretexto, para colmo, de piedad y religión), que aquí se ha estado desgarrando a veces, con muchas torturas, un cuerpo lleno de vida, asándolo a fuego lento y entregándolo a los mordiscos y desgarros de carne y puercos. Esto es más bárbaro que asar y comer a un hombre ya difunto". Montaigne, Michel de: Ensayos, Vol. I, Edit. Ibérica, Barcelona, [1580] 1968, pág. 156).

53 Fernández de Oviedo, Historia, Tomo 119, Libro XXIX, Cap. X, 1959, pág. 241. Un poco más adelante, Oviedo matiza sus críticas y postula que "ni tampoco es aquesto sólo la causa de la destruición e asolación de los indios, aunque harta parte para ello ha causado esta mixtura; mas, juntos los materiales de los inconvenientes ya dichos, con los mesmos delictos e sucias e bestiales culpas de los indios sodomitas, idolatrías, e tan familiares e de tan antiquísimos tiempos en la obidiencia e servicio del diablo, e olvidados de nuestro Dios trino e uno, pensarse debe que sus méritos son capaces de sus daños, e que son el principal cimiento sobre que se han fundado e permitido Dios las muertes e trabajos que han padescido e padescerán todos aquellos que sin baptismo salieron desta temporal vida.” (Ibidem: pág. 355).

54 Pastor: The Armature of Conquest..., págs. 101 y ss. 
anterior. Al contrario, Oviedo lo retrata como un agresor, un individuo cruel que participó en multitud de asesinatos y traiciones, y que, lejos de reflejar los intereses de la Corona, los acaba traicionando. La intención del cronista es cristalina. Denunciar la conducta de Pedrarias conlleva ensalzar las propias acciones como un ejemplo de lealtad y servicio que merecen la máxima recompensa. ${ }^{55}$ Frente a la amenaza que supone para el orden colonial el desgobierno del segoviano, Oviedo propondrá en la audiencia convocada en Barcelona en 1519 su propio modelo de gobierno. Uno basado en buenos vasallos, hombres virtuosos y de buena casta, leales a la Corona y que puedan salvaguardar sus intereses en el Nuevo Mundo. ${ }^{56}$ La construcción caballeresca y cortesana que Oviedo hace de sí mismo contrasta con la figura de Pedrarias. El primero, reflejo de la voluntad del rey; el segundo, traición y vileza que merecen su justo castigo. ${ }^{57}$

La cimentación del héroe cristiano había simplificado enormemente la personalidad del conquistador-descubridor en la Historia. Con su desaparición, éste recupera buena parte de su complejidad. Oviedo lo convierte en el centro de la narración, pero alejado ya de aquellos valores caballerescos que habían caracterizado a Ponce de León o al mismo Hernán Cortés. Ahora se trata de narrar de forma episódica multitud de fracasos, campañas mal planificadas y naufragios en un intento de presentar la otra cara de la conquista. Una cara amarga, desesperada, que refleja el espíritu contradictorio y políticamente subversivo del conquistador. Un conquistador que se nos antoja mucho más humano y menos mítico y heroico que antes. ${ }^{58}$

Sin embargo, la deconstrucción del héroe cristiano no debería analizarse como una reacción contra el imperialismo español. Oviedo nunca cuestionará la presencia española en el Nuevo Mundo. Ni tampoco la autoridad de su rey. ${ }^{59}$ Era una consecuencia lógica de la superioridad intelectual y

55 Ibidem: pág. 128.

56 Fernández de Oviedo, Historia, Libro XXVI, Cap. I, 1959, pág. 62.

57 La personalidad violenta y agresiva de Pedrarias es a menudo contrastada con la "valerosa persona" de Vasco Núñez de Balboa, quien, a juicio de Oviedo, fue "uno de los mejor partidos capitanes que a estas Indias han pasado". Fernández de Oviedo, Historia, Libro XXIX, Cap. III, 1959, pág. 221.

58 Pastor: The Armature of Conquest..., págs. 183-184.

59 Uno de los pocos que lo hizo fue Lope de Aguirre. En 1559, se alistó para una expedición a Omagua y El Dorado. Tres meses después, asesina al jefe de la expedición amazónica, Don Pedro de Ursúa, abandona el proyecto de buscar Omagua y planea regresar al Perú para apoderarse del país y traicionar a su rey, erigiendo una monarquía independiente. Al respecto, véase Lope de Aguirre: crónicas 1559-1561. Edición de Mampel González, Elena y Escandell-Tur, Neus Ediciones de la Universitat de Barcelona, Barcelona, 1981; Pastor, Beatriz: "Lope de Aguirre The Wanderer: Knowledge and Mandes". Dispositio, Vol. 11, n.os 28/29, 1986, págs. 85-98; Ibidem: "Lope de Aguirre el Loco: la voz de la soledad". Revista de crítica literaria latinoamericana, Vol. XIV, n. ${ }^{\circ} 28,1988$, págs. 159-173. 
moral de los españoles. La Historia es vista ahora como un relato para juzgar moralmente la conducta de los "malos españoles". Así, los designios de la Divina Providencia quedan a salvo al exorcizar las causas del mal. Es en este sentido que el cronista ensalza su papel como "testigo ocular" de los hechos que relata. La verdad sólo puede ser narrada por aquellos que han vivido - y sufrido - las experiencias que cuentan. ${ }^{60}$ Conceptos como civilización, canibalismo o barbarie revelan su vulnerabilidad como conceptos explicativos de la superioridad española en el Nuevo Mundo. Héroes y villanos son todos seres humanos que sufren, dudan y padecen. Tras el desastre de Argel de 1541, la Corona dará un paso adelante en la protección del indio americano con publicación de las Leyes Nuevas de Indias en 1542, e intentará imponer su autoridad limitando el poder de los encomenderos. No en vano Oviedo relativiza su discurso imperial en un intento de adaptarse a los nuevos tiempos. Incluso aquellos indios mansos, desprovistos de razón, adquirirán una progresiva conciencia crítica a través de la persuasión (lascasiana). Una inversión de papeles que Oviedo utiliza como un recurso narrativo para denunciar a sus compatriotas (conquistadores, clérigos, letrados), acusándolos de comportarse como aquellos a los que supuestamente había que evangelizar. La Historia se convierte así en una fuente de verdad que amplifica las iniquidades del enemigo, ya sea indio o español, y justifica las propias en un intento de salvaguardar - y proteger- la voluntad real ${ }^{61}$.

A pesar de sus esfuerzos, el desengaño de Oviedo no pudo ser más elocuente. La relación directa entre el Rey y sus vasallos se rompe; en su lugar, aparecen multitud de burócratas —o letrados- que buscarán satisfacer sus intereses personales, anteponiéndolos a los de la Corona. Si servir al rey era lo que proporcionaba más honra, servirlo mal era motivo de vergüenza y deshonra. ${ }^{62} \mathrm{~A}$ pesar de ello, algunos españoles de comporta-

60 Como señala Mendiola, hay una relación estrecha entre el comportamiento moral y el acceso a la verdad que se remonta a la antigüedad griega. Sólo se alcanza ésta si uno se comporta moralmente. Mendiola, Retórica..., págs. 150-151.

61 Respecto al sentido común de Oviedo con respecto al nuevo contexto político surgido a raíz de las Leyes Nuevas (1542), véase Pérez de Tudela Bueso, Juan: "Vida y escritos de Gonzalo Fernández de Oviedo", en la Introducción a la Historia General y Natural de las Indias, Madrid: Biblioteca de Autores Españoles, 1959, CXXXIV. Un análisis similar puede encontrarse en Rabasa, José: "The Representation of Violence in the Soto narratives", en Galloway, Patricia (eds.): The Hernando de Soto Expedition. History, Historiography, and "Discovery" in the Southeast, Lincoln \& London: University of Nebraska Press, 1997, págs. 394.

62 Caro Baroja, Julio: "Honor y vergüenza. Examen histórico de varios conflictos", en Peristany, J. G.: El concepto de honor en la sociedad mediterránea, Edit. Labor, Barcelona, 1968, págs. 97-98. 
miento indigno, como Hernando de Soto o Pánfilo de Narváez, conseguirán un reconocimiento superior al que obtuvo Oviedo en vida: el hábito de Santiago. No en vano las cualidades personales características del héroeconquistador - honor, dignidad, valentía, justicia - desaparecen; en su lugar, adoptarán las "virtudes" atribuidas a los indios: crueldad, violencia, desmesura. Lejos de plantear unos modelos idealizados de conducta, Oviedo elaboró una imagen mucho más convencional y realista de las actividades de sus compatriotas. Una que refleja su disconformidad con el pillaje y el derecho de conquista que practicaban. Por el contrario, la maldad de los indios queda en suspenso. Algunos incluso aparecen despojados de sus perversas costumbres, rudeza de ingenio y brutal inclinación, y por primera vez, se dirigen al lector y le hablan. ${ }^{63}$ Este recurso literario refleja no sólo las intenciones del narrador, sino la asimilación de los indios americanos en las coordenadas históricas de Occidente.

63 Según Joan Lluís Vives (1492-1540), el lenguaje surgió de palabras aisladas, dando lugar a combinaciones lingüísticas entre los hablantes que acabaron formando frases y una gramática general. La importancia concedida a las formas gramaticales revelaba el grado de cultura de un pueblo, la manifestación exterior de su pensamiento (De tradentis disciplinis, 1531). 